\title{
West Nile virus: a growing concern?
}

\section{Hannah Gould and Erol Fikrig}

\author{
Department of Epidemiology and Public Health and Section of Rheumatology, and Department of Internal Medicine, \\ Yale University School of Medicine, New Haven, Connecticut, USA.
}

\begin{abstract}
West Nile virus was first detected in North America in 1999 and has subsequently spread throughout the United States and Canada and into Mexico and the Caribbean. This review describes the epidemiology and ecology of West Nile virus in North America and the prospects for effective treatments and vaccines.
\end{abstract}

\section{Introduction and epidemiology}

West Nile virus (WNV), a member of the family Flaviviridae, genus Flavivirus, was first isolated from the serum of a febrile woman in 1937 in the West Nile district of Uganda (1). Following its original isolation, WNV was implicated as the cause of sporadic outbreaks of mild viral illness in Africa, the Middle East, western Asia, and Australia (Kunjin virus subtype) (2, 3). Since the 1990s, however, WNV outbreaks have also occurred in Europe and North Ameri$\mathrm{ca}$, and these recent outbreaks have been associated with higher rates of viral encephalitis and other neurological symptoms (2-4).

In August and September 1999, a cluster of encephalitis cases caused by WNV was identified in New York City $(5,6)$. Previously unidentified in North America, the WNV epidemic in 1999 was responsible for seven human fatalities, as well as the death of hundreds of birds and horses in New York, New Jersey, and Connecticut. Although the virus spread westward during the next two years, only modest disease activity was seen until 2002, when the number of cases increased dramatically, and by the end of 2003 the epizootic had spread to all but two of the lower 48 states $(7,8)$. The number of cases of WNV has also continued to rise (4); by midFebruary 2004, 9175 human cases and 230 deaths were reported as a result of the 2003 outbreak $(7,9)$.

The range of WNV in the Western Hemisphere has continued to expand, and in addition to the United States, virus activity has been detected in Canada, Mexico, and the West Indies (Figure 1). In Canada, WNV was first isolated from birds in 2001 and humans in 2002, and by the end of 2003, disease activity had spread to a total of nine provinces and territories (10). In 2002, WNV-neutralizing antibodies were detected in samples from birds captured in Jamaica, the Dominican Republic, and Guadeloupe (11-13), and horses in Mexico (14), suggesting establishment of the virus in the neotropics. Although only one human case has been reported from the Caribbean (15), virus activity in birds and horses suggests that human cases may soon be regularly detected in these areas. In the United States, human infections occur from May to December, with $85 \%$ of cases occurring in August and September. In the neotropics, however, transmission is likely to occur year-round and WNV may pose a significant public health problem in future years. Additionally, because the Caribbean region serves as the wintering ground for many migratory birds, presence of the virus in this region is likely to contribute to the maintenance of virus in its avian reservoirs.

Nonstandard abbreviations used: cerebrospinal fluid (CSF); envelope (E); intravenous immunoglobulin (IVIG); Japanese Encephalitis virus (JEV); premembrane (prM); Saint Louis Encephalitis virus (SLEV); West Nile virus (WNV).

Conflict of interest: The authors have declared that no conflict of interest exists.

Citation for this article: J. Clin. Invest. 113:1102-1107 (2004).

doi:10.1172/JCI200421623.
WNV is classified into two lineages. Lineage 1 viruses are responsible for human disease while lineage 2 viruses are found primarily in enzootic cycles in Africa and typically do not cause severe, neurologic illness in humans, although significant outbreaks of lineage $2 \mathrm{WNV}$ have occurred (16). The lineage 1 virus found in North America is almost genetically identical to a strain circulating in Israel from 1997-2000, suggesting a potential origin of the North American epidemic $(6,17,18)$. Since its importation the virus has undergone only minor genetic evolution, suggesting a lack of strong selective pressure (19); however, the virus may change more rapidly as immune responses to WNV become more common in reservoir hosts. While it is still unknown how WNV first reached North America, a number of theories have been advanced, including introduction by a viremic human or bird, or the accidental importation of a WNV-infected mosquito. Because humans infected with WNV have only a low and transient viremia, it is unlikely that WNV was introduced by an infected person. Although it is possible that a migratory bird blown off its flight path introduced the virus, this is also doubtful, as the bird would need to have maintained a high viremia over a considerable period of time. Evidence of direct transmission within some birds suggests that the introduction of a bird with a low viremia could potentially have been sufficient to pass and amplify the virus for subsequent transmission from mosquito to humans.

\section{Ecology}

WNV is maintained in an enzootic bird-mosquito-bird cycle (Figure 2). In Africa, southern Europe, and western Asia, WNV has been isolated from mosquitoes of more than 40 species, primarily those in the genus Culex (3); in the United States, WNV has been isolated from mosquitoes belonging to 43 species since $1999(9,15)$. In the United States the majority of WNV isolates have been from Culex species, particularly $C x$. pipiens, $C x$. restuans, and $C x$. salinarius; however, isolates have also been recovered from species in other genera, including Aedes, Anopheles, Coquillettidia, and Ochlerotatus $(15,20)$. Culex species are the most important maintenance vectors within the avian cycle, with other species serving as bridge vectors from birds to humans and horses in mid to late summer. While mosquitoes belonging to many species are competent vectors of the virus in the laboratory, their vector competence in humans is still unknown. In the northeastern and southern US transmission among birds is likely mediated by $C x$. pipiens; however, the most important bridge vectors to humans are unidentified. The large outbreak of WNV in the western US, especially Colorado, in 2003 was likely due to $C x$. tarsalis, an indiscriminant feeder on both birds and mammals. In regions where the same vector contributes to both the mammalian and the avian cycles, disease activity will continue to be more pronounced. WNV has also been isolated from 


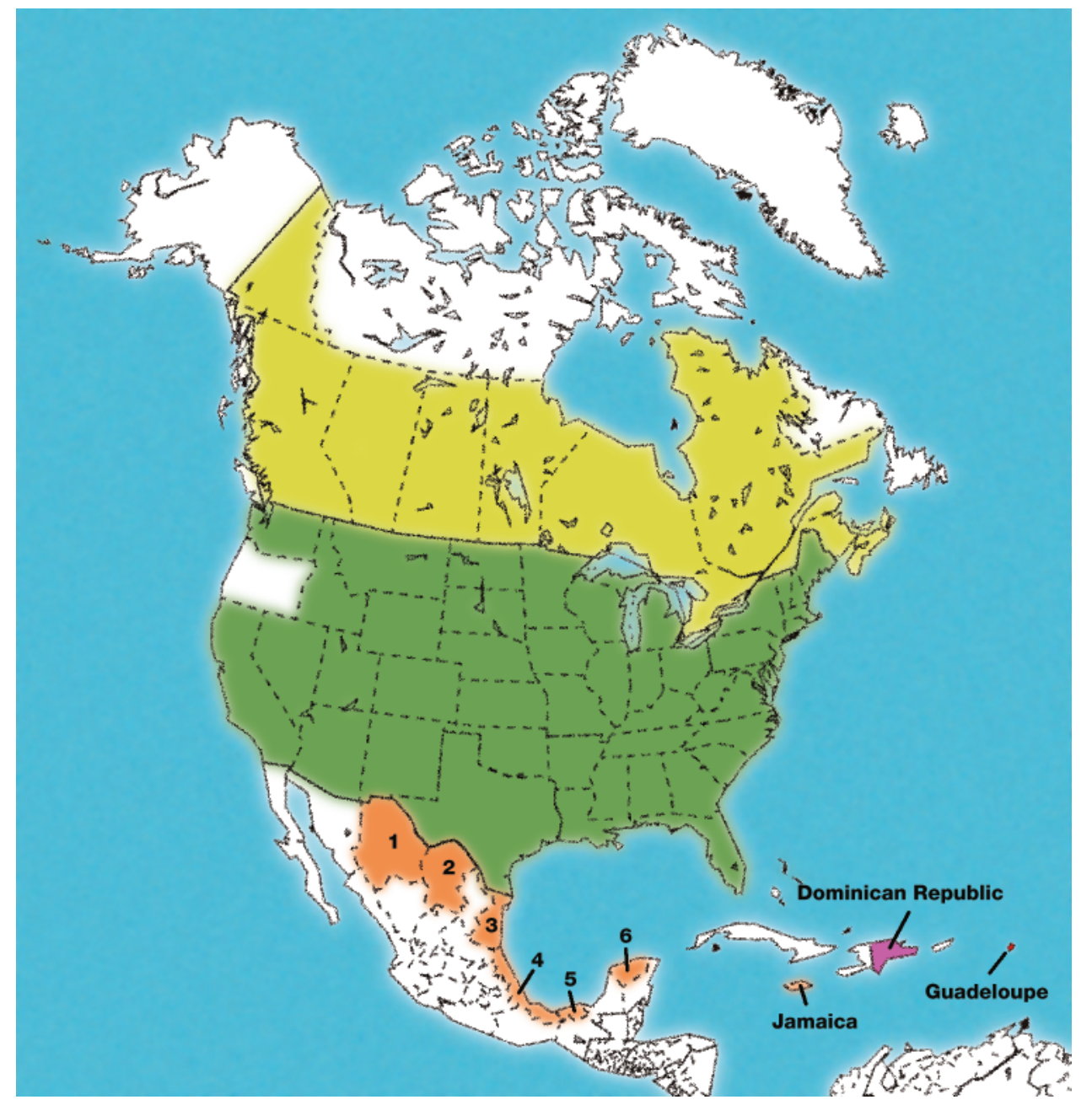

\section{Figure 1}

WNV activity in North America as of January 2004. Shading represents areas in which virus activity has been recorded. 1, Chihuahua; 2, Coahuila; 3, Tamaulipas; 4, Veracruz; 5, Tabasco; 6, Yucatan. both hard and soft ticks; however, the ability of ticks to successfully and significantly transmit the virus in nature is unclear $(21,22)$.

In the United States, Canada, and Israel, WNV is responsible for significant avian mortality. WNV has been isolated from 198 bird species in North America (23), and mortality may approach $100 \%$ in some species (24). Passerine birds, including crows, house sparrows, and blue jays, serve as the primary amplifying hosts of the virus, and develop a high-level viremia that lasts for several days (24). A study of WNV transmission in 25 species of birds found cloacal shedding of virus in 17 of 24 species and oral shedding in 12 of 14 species (24). In addition, contact transmission was identified in four species, and oral transmission in five species (24). Although the precise contribution of direct transmission to disease activity among birds has not been quantified, it has potentially significant implications for disease epidemiology, because even with effective vector control virus may be amplified and transmitted. Direct transmission may be aggravated in commercial settings because of cannibalism and feather-picking of sick birds (25).

In contrast to some bird species, in which high-level viremia is seen, humans and horses develop only low-level and transient viremia and are unlikely to contribute to virus amplification (26, 27). WNV infection has also been demonstrated in a number of other wild vertebrate species, including wolves, bears, crocodiles, alligators, and bats (28-31), and in domestic animals, including cats and dogs $(28,32)$. Because of the low viremia in many of these species, it is similarly unlikely that they contribute to the amplification of the virus, but instead serve as dead-end hosts.

\section{Routes of transmission}

Most human infections of WNV are the result of transmission of the virus by infected mosquitoes; however, several novel modes of transmission are now recognized in the United States (Figure 2). Taken together, these new modes of transmission suggest a complex epidemiology of this disease, and have important implications for the control and containment of WNV infection. Because of the low incidence of WNV worldwide until recently, it is unclear whether these novel modes of transmission have always been present but rare or if the epidemiology of the virus is truly changing. As WNV continues to expand, an awareness of these additional, nonvector modes of transmission are crucial to effective surveillance and disease control.

The first case of intrauterine WNV transmission was reported in 2002. A pregnant woman in her second trimester was infected with WNV and subsequently transmitted the virus to her fetus in utero. The infant, delivered at term, had bilateral chorioretinitis, severe cerebral abnormalities, and serum and cerebrospinal fluid (CSF) WNV-specific IgM and WNV-neutralizing antibodies (33). Mother-to-child transmission of WNV via breast milk has also been identified; the lactating mother had acquired WNV from a blood trans- 


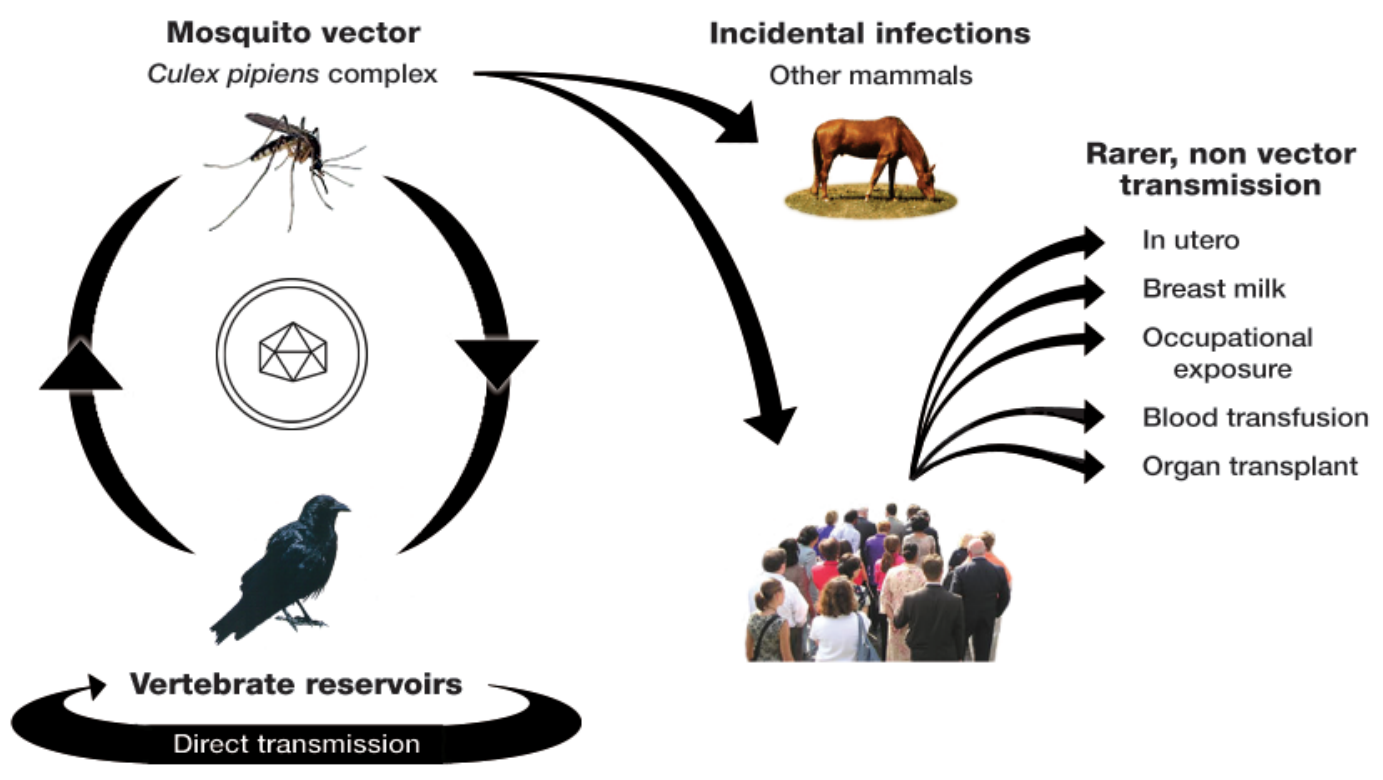

Figure 2

WNV is maintained in an enzootic mosquito-bird-mosquito cycle. Humans and other mammals serve as dead-end hosts and do not sufficiently amplify virus for mosquito transmission, although they may transmit or acquire virus in utero, through breast milk, via blood transfusion or organ transplantation, or through occupational exposure. fusion (34). Intrauterine infection with either Japanese Encephalitis virus (JEV) or a dengue virus has been associated with spontaneous abortion and severe dengue infection in the infant $(35,36)$. Pregnant women in regions with high risk of WNV should take precautions to reduce their disease risk; however, given the low incidence of intrauterine transmission, routine screening of pregnant women is not indicated at the current time.

Several cases of WNV infection due to occupational exposure have been documented. In two cases reported by the Centers for Disease Control and Prevention in 2002, exposure of laboratory workers occurred through accidental inoculation (37). In one of these cases the infected individual possessed heterologous Flavivirus antibodies; however, these did not confer protection against infection with WNV, although the severity of the illness may have been reduced (37).

In late 2002, two cases of WNV were reported in workers at a turkey-breeding farm in Wisconsin (38). A survey of workers at this farm revealed a higher prevalence of WNV antibodies and incidence of febrile illness than in workers at several other local turkey farms and meat processing facilities or in the local citizens who lived near the affected farm. In addition, WNV seroprevalence was nearly $100 \%$ among birds at this facility. Because turkeys do not develop sufficient viremia to serve as amplifying hosts for WNV transmission by mosquitoes, it is likely that nonvector transmission was responsible for this outbreak (39). While the mode of transmission to the workers remains unclear, this outbreak was likely due to an occupational exposure, perhaps due to percutaneous injury or aerosol exposure to turkey feces. This finding has important implications for individuals who work in areas with high concentrations of potentially infected animals, and precautions beyond those recommended to prevent mosquito bites should be widely implemented.

In 2002, 23 people were reported to have acquired WNV from blood components collected from $16 \mathrm{WNV}$-viremic blood donors, and as many as $500 \mathrm{WNV}$-positive donations may have been collected. In response to these cases, blood collection agencies implemented nucleic acid amplification tests to screen donations for WNV in 2003. Between late June and mid-September 2003, 0.05\% of approximately 2.5 million blood donations screened tested pos- itive for WNV and 489 WNV-viremic blood donors were identified. Nearly $90 \%$ of viremic donors remained asymptomatic and only two developed WNV-associated meningoencephalitis. Despite this extensive screening, two cases of transfusion-associated WNV transmission were identified in 2003 (40). The infectious donors in both cases were identified and retested, and both were found to have seroconverted. Whether these infectious blood products escaped detection due to a very low viremia or test efficacy is unknown (41). In the future, blood collection agencies should consider additional methods, such as inactivation of the pathogen in blood products, as the risk of WNV infection from blood transfusion remains.

In August 2002, WNV was identified in an organ donor and four transplant recipients. The organ donor had received blood components from 63 individuals, one of whom was subsequently identified as WNV-seropositive. Three of the organ recipients developed encephalitis and one developed a febrile illness (42). Several additional cases of WNV transmission by organ transplantation have subsequently been reported $(43,44)$.

Prevention of WNV transmission by organ transplantation or transfusion of blood components relies on the accurate exclusion of viremic donors. Nucleic acid tests were introduced in blood donor screening in 2003, and may prove useful for routine diagnosis in the future, especially in immunocompromised patients with impaired antibody development. As seen in 2003, screening of blood donors can significantly reduce the incidence of transfusion of contaminated blood; however, more sensitive tests are needed to identify potential donors with very low levels of viremia. Routine screening of the blood supply and of organ donors is probably too costly to be warranted; however, during the summer months in locations with a high level of virus activity, such measures should be encouraged and are necessary to reduce transmission to already immunocompromised individuals.

\section{Virus detection}

Laboratory findings show mostly normal or elevated leukocyte counts in peripheral blood samples (45). CSF samples of patients with neurologic manifestations show pleocytosis, usually with a predominance of lymphocytes and elevated protein levels (45-47). 
Computerized axial tomography scans of the brain tend to reveal no evidence of acute disease; magnetic resonance imaging findings from most patients are normal but can show lesions in the pons, basal ganglia, and thalamus as well as enhancement of the leptomeninges and/or the periventricular areas $(46,47)$.

The presence of IgM antibody in the serum or CSF is the most efficient and reliable indicator of infection. The IgM antibody-capture ELISA (MAC-ELISA) test is considered the most reliable (45, 46). IgM antibody does not readily cross the blood-brain barrier, so its presence in the CSF indicates infection of the CNS. More than $90 \%$ of patients with meningoencephalitis have $\operatorname{IgM}$ antibody in the CSF within 8 days of symptom onset (48).

Because of the close antigenic relationships among some of the flaviviruses, laboratory findings must be interpreted with care. Persons recently vaccinated against or infected with another Flavivirus may have IgM antibody to WNV. While tests exist that help distinguish infections, the persistence of IgM antibody for longer than 500 days in a small proportion of patients, the fact that most cases are asymptomatic, and the presence of IgM antibody may reflect a previous infection with an unrelated Flavivirus or vaccination against a Flavivirus, such as Yellow Fever virus $(46,49)$. Two newly developed and highly sensitive assays, based on nonstructural protein 5 (50) and a recombinant form of the envelope (E) protein (51), reliably distinguish between infections with WNV, dengue viruses, and SLEV, differentiate between immunity from vaccination and natural infection, indicate recent infection status, and may shorten testing time to less than three hours $(50,51)$.

\section{Treatment and vaccine prospects}

Most infections with WNV are clinically inapparent and go undetected. A serosurvey in 1999 in New York showed that only approximately $20 \%$ of infected persons developed fever caused by WNV, and of these, only about half visited a physician for their illness (52). Approximately 1 in 150 patients progress to severe neurologic illnesses (encephalitis, meningitis, acute flaccid paralysis), and while prevalence rates are fairly uniform across age-groups, rates of neurological disease increase substantially with age, as does the clinical:subclinical infection ratio $(53,54)$. Case-fatality rates among hospitalized patients have ranged from 4\% (Romania, 1996) to $12 \%$ in the New York 1999 outbreak and as high as $14 \%$ in an outbreak in Israel in 2000. Advanced age is the main risk factor for death, with individuals more than 70 years of age at particularly high risk. Among such individuals, the case-fatality rate ranges from $15 \%$ to $29 \%$ (45). The reason for increased mortality in the elderly is not yet known but may be related to a decreased capacity of these individuals to develop a protective immune response to help control infection. Clearly, in mice, select populations of immune cells including B cells (55), $\gamma \delta$ T cells (56), and $\mathrm{CD}^{+} \mathrm{T}$ cells (57) are important in both immunity against and the pathogenesis of WNV. Future studies in humans, guided in part by experimental work in animal models, will determine whether selected immune responses to WNV are decreased in the elderly, leading to new strategies to treat disease.

Currently, the only treatments for WNV infection are supportive. In vitro studies have found ribavirin and IFN- $\alpha 2 b$ to be effective against the virus; however, a patient treated with both agents did not improve, and there have been no controlled clinical trials of either agent (58-60). Because the induction of a WNV-specific, neutralizing response early in the course of murine WNV infection limits viremia and dissemination into the CNS, antibodies may be effective as both prophylaxis and therapy for WNV infection, particularly in the elderly, who have decreased antibody production and limited response following vaccination (61). In mice administered human gamma globulin prior to infection, protection against disease was afforded and clinical outcome improved even after the virus had spread to the CNS $(62,63)$. Most significantly, antibody-dependent enhancement of infection - a phenomenon that is associated with severe hemorrhagic syndrome in secondary infections with dengue viruses - was not observed (64).

Several human case reports indicate that treatment with intravenous immunoglobulin (IVIG) may aid in recovery from infection (65-67). A number of questions must be resolved to determine the efficacy of IVIG as therapy in humans. Of critical importance is the window in which passive therapy is effective. In animal models, the use of IVIG appears effective before or immediately after viral challenge; however, once cerebral infection occurs, use is limited (68). Because the precise timing of infection in a human being is usually undetermined and most individuals do not present to their clinician prior to severe illness, administration of antibodies may provide limited use therapeutically. As prophylaxis, however, antibodies could prove useful for individuals at high risk of infection (69). Hamsters administered immunoglobulin 24 hours prior to infection were completely protected from infection (70), indicating that passive immunization may serve as a vaccine strategy for short-term, immediate exposures in individuals at high risk. In addition, the dose of antibody required to boost the immune response must be addressed. Given the lack of current treatments for WNV and the paucity of case reports supporting the utility of antibody therapy, a controlled clinical trial of immunoglobulin therapy is warranted to determine dose, timing, and efficacy more completely.

A variety of $\mathrm{WNV}$ vaccine candidates are in various stages of testing. Because of the low incidence of disease in humans and the sporadic nature of most outbreaks, it is difficult to target human populations for vaccination and to assess the economic feasibility of a human vaccine. An equine vaccine has been in use since 2001, and was licensed by the United States Department of Agriculture in 2003. This vaccine is a formalin-inactivated WNV, and was found to prevent development of viremia in $94 \%$ of immunized horses (71). Killed vaccines, while safe, may have to be administered in multiple doses to elicit and sustain an immune response, and the manufacturer of the commercially available vaccine recommends annual revaccination. A live attenuated $\mathrm{WNV} /$ dengue virus serotype 4 chimera also produced a strong neutralizing antibody response and prevented viremia in monkeys challenged with WNV (72). Two live attenuated virus variants have been used successfully to prevent infection in geese (73).

Several vaccines have been developed based on WNV structural proteins. As the predominant surface glycoprotein and the primary target of WNV-neutralizing antibodies $(74,75)$, the E protein is the most likely candidate for a successful vaccine. An experimental chimeric WNV vaccine candidate containing the premembrane (prM) and E genes from wild-type New York 1999 virus within the Yellow Fever $17 \mathrm{D}$ vaccine virus $(76,77)$ elicits a strong and potentially long-lasting humoral immune response in a hamster model (78). Additional vaccine candidates include recombinant DNA vaccines expressing the prM and E (79) or capsid proteins (80), and a recombinant $\mathrm{E}$ protein subunit vaccine (81). While it is likely that several of these vaccines will be effective, the benefits and risks of vaccination remain to be determined. In general, live attenuated 
vaccines often have a higher perceived risk than recombinant antigens, and may not receive enthusiastic public support. As most people in areas of virus activity are exposed to mosquitoes, the vaccine could be made widely available; however, since the risk of acquiring WNV is relatively low, this does not seem warranted at the present time. Perhaps a vaccine that targets elderly and immunocompromised individuals in high-risk areas would be an appropriate initial strategy.

Several studies have assessed the efficacy of heterologous Flavivirus vaccines against WNV. Partial cross-protective immunity has been generated in hamsters and mice using JEV, Yellow Fever virus, Saint Louis Encephalitis virus (SLEV), and dengue virus vaccines $(70,82)$; however, a study of human volunteers showed no WNVneutralizing antibodies after vaccination against either JEV or a dengue virus (83). While vaccination with JEV or Yellow Fever virus may not prevent infection with $\mathrm{WNV}$, such vaccination may limit disease severity and progression. Vaccination with the WNV subtype Kunjin virus-based DNA vaccine protected mice against WNV infection, and may serve as an effective vaccination strategy because of the close antigenic relationship between the Kunjin subtype and the strain infecting North America (84). Likewise, it is theoretically possible that a WNV vaccine could afford partial protection against other flaviviral infections.

\section{Future directions}

WNV was initially diagnosed as SLEV when it appeared in New York in 1999. In North America these two viruses share similar mosquito vectors and avian hosts, and may share a common epidemiologic pattern. SLEV is the cause of sporadic outbreaks that are difficult to predict and which cause a highly variable number of cases, ranging from a handful to more than 2000 in the 1975 epidemic $(46,85)$. While there are many similarities between these two viruses, the sustained levels of WNV activity of the past few years combined with the complex epidemiology of transmission, the high levels of viremia seen in wild reservoirs, and the large number of species of mosquitoes that have been found infected with this virus, suggest that WNV will be a greater challenge for the public health system and clinicians than SLEV. As WNV continues to spread in the Western Hemisphere, it is likely that transmission will become a year-round, constant presence. The need for effective vaccines and treatments is increasing in importance as this disease continues to expand its range and increase in severity.

Address correspondence to: Erol Fikrig, Yale University School of Medicine, S525 TAC, 300 Cedar Street, New Haven, Connecticut 06520, USA. Phone: (203) 785-2453; Fax: (203) 785-7053; E-mail: erol.fikrig@yale.edu.
1. Smithburn, J.S., Hughes, T.P., Burke, A.W., and Paul, J.H. 1970. A neurotropic virus isolated from the blood of a native of Uganda. Am. J. Trop. Med. Hyg. 20:471-492.

2. Monath, T.P. 1990. Flaviviruses. In Virology. B.N Fields and D.M. Knipe, editors. Raven Press. New York, New York, USA. 763-814.

3. Hayes, C.G. 1989. West Nile fever. In The arboviruses: epidemiology and ecology. T.P. Monath, editor. CRC Press. Boca Raton, Florida, USA. 59-88.

4. Marfin, A.A., and Gubler, D.J. 2001. West Nile encephalitis: an emerging disease in the United States. Clin. Infect. Dis. 33:1713-1719.

5. Anderson, J.F., et al. 1999. Isolation of West Nile virus from mosquitoes, crows, and a Cooper's hawk in Connecticut. Science. 286:2331-2333.

6. Lanciotti, R.S., et al. 1999. Origin of the West Nile virus responsible for an outbreak of encephalitis in the northeastern United States. Science. 286:2333-2337.

7. CDC. 2003. West Nile virus activity - United States, November 20-25, 2003. Morb. Mortal. Wkly Rep. 52:1160.

8. CDC. 2002. Provisional surveillance summary of the West Nile virus epidemic - United States, January-November 2002. Morb. Mortal. Wkly Rep. 51:1129-1133.

9. CDC. Division of vector-borne infectious diseases. West Nile virus. http://www.cdc.gov/ncidod/dvbid/ westnile/.

10. Health Canada. West Nile virus. http://www.hc-sc. gc.ca/english/westnile/.

11. Dupuis, A.P., II, Marra, P.P., and Kramer, L.D. 2003. Serologic evidence of West Nile virus transmission, Jamaica, West Indies. Emerg. Infect. Dis. 9:860-863.

12. Komar, O., et al. 2003. West Nile virus transmission in resident birds, Dominican Republic. Emerg. Infect. Dis. 9:1299-1302.

13. Quirin, R., et al. 2004. West Nile Virus, Guadeloupe. Emerg. Infect. Dis. http://www.cdc.gov/ncidod/EID/ vol10no4/03-0465.htm

14. Lorono-Pino, M.A., et al. 2003. Serologic evidence of West Nile virus infection in horses, Yucatan State, Mexico. Emerg. Infect. Dis. 9:857-859.

15. 2002. West Nile Virus activity - United States, 2001. Morb. Mortal. Wkly Rep. 51:497-501.

16. Jupp, P.G. 2001. The ecology of West Nile virus in
South Africa and the occurrence of outbreaks in humans. Ann. N. Y. Acad. Sci. 951:143-152.

17. Briese, T., Jia, X.Y., Huang, C., Grady, L.J., and Lipkin, W.I. 1999. Identification of a Kunjin/West Nilelike flavivirus in brains of patients with New York encephalitis. Lancet. 354:1261-1262.

18. Jia, X.Y., et al. 1999. Genetic analysis of West Nile New York 1999 encephalitis virus. Lancet. 354:1971-1972.

19. Beasley, D.W., et al. 2003. Limited evolution of West Nile virus has occurred during its southwesterly spread in the United States. Virology. 309:190-195.

20. Turell, M.J., Sardelis, M.R., Dohm, D.J., and O'Guinn, M.L. 2001. Potential North American vectors of West Nile virus. Ann. N. Y. Acad. Sci. 951:317-324.

21. Abbassy, M.M., Osman, M., and Marzouk, A.S. 1993. West Nile virus (Flaviviridae:Flavivirus) in experimentally infected Argas ticks (Acari:Argasidae). Am. J. Trop. Med. Hyg. 48:726-737.

22. Anderson, J.F., Main, A.J., Andreadis, T.G., Wikel, S.K., and Vossbrinck, C.R. 2003. Transstadial transfer of West Nile virus by three species of ixodid ticks (Acari: Ixodidae). J. Med. Entomol. 40:528-533.

23. Komar, N. 2003. West Nile virus: epidemiology and ecology in North America. Adv. Virus Res. 61:185-234.

24. Komar, N., et al. 2003. Experimental infection of North American birds with the New York 1999 strain of West Nile virus. Emerg. Infect. Dis. 9:311-322.

25. Banet-Noach, C., Simanov, L., and Malkinson, M. 2003. Direct (non-vector) transmission of West Nile virus in geese. Avian Pathol. 32:489-494.

26. Southam, C.M., and Moore, A.E. 1954. Induced virus infections in man by the Egypt isolates of West Nile virus. Am. J. Trop. Med. Hyg. 3:19-50.

27. Bunning, M.L., et al. 2001. Experimental infection of horses with West Nile virus and their potential to infect mosquitoes and serve as amplifying hosts. Ann. N. Y. Acad. Sci. 951:338-339.

28. 2000. Update: West Nile virus activity - eastern United States, 2000. Morb. Mortal. Wkly Rep. 49:1044-1047.

29. Farajollahi, A., et al. 2003. Serologic evidence of West Nile virus infection in black bears (Ursus americanus) from New Jersey. J. Wildl. Dis. 39:894-896.
30. Steinman, A., et al. 2003. West Nile virus infection in crocodiles. Emerg. Infect. Dis. 9:887-889.

31. Miller, D.L., et al. 2003. West Nile virus in farmed alligators. Emerg. Infect. Dis. 9:794-799.

32. Blackburn, N.K., Reyers, F., Berry, W.L., and Shepherd, A.J. 1989. Susceptibility of dogs to West Nile virus: a survey and pathogenicity trial. J. Comp. Pathol. 100:59-66.

33. 2002. Intrauterine West Nile virus infection - New York, 2002. Morb. Mortal. Wkly Rep. 51:1135-1136.

34. 2002. Possible West Nile virus transmission to an infant through breast-feeding - Michigan, 2002. Morb. Mortal. Wkly Rep. 51:877-878.

35. Chaturvedi, U.C., et al. 1980. Transplacental infection with Japanese encephalitis virus. J. Infect. Dis. 141:712-715.

36. Chye, J.K., et al. 1997. Vertical transmission of dengue. Clin. Infect. Dis. 25:1374-1377.

37. 2002. Laboratory-acquired West Nile virus infections - United States, 2002. Morb. Mortal. Wkly Rep. 51:1133-1135.

38. 2003. West Nile virus infection among turkey breeder farm workers - Wisconsin, 2002. Morb. Mortal. Wkly Rep. 52:1017-1019.

39. Swayne, D.E., Beck, J.R., and Zaki, S. 2000. Pathogenicity of West Nile virus for turkeys. Avian Dis. 44:932-937.

40. 2003. Update: Detection of West Nile virus in blood donations - United States, 2003. Morb. Mortal. Wkly Rep. 52:916-919.

41. 2003. Detection of West Nile virus in blood donations - United States, 2003. Morb. Mortal. Wkly Rep. 52:769-772.

42. Iwamoto, M., et al. 2003. Transmission of West Nile virus from an organ donor to four transplant recipients. N. Engl. J. Med. 348:2196-2203.

43. DeSalvo, D., et al. 2004. West Nile virus encephalitis in organ transplant recipients: another highrisk group for meningoencephalitis and death. Transplantation. 77:466-469.

44. Kumar, D., Prasad, G.V., Zaltzman, J., Levy, G.A., and Humar, A. 2004. Community-acquired West Nile virus infection in solid-organ transplant recipients. Transplantation. 77:399-402.

45. Petersen, L.R., and Marfin, A.A. 2002. West Nile virus: a primer for the clinician. Ann. Intern. Med. 137:173-179. 
46. Campbell, G.L., Marfin, A.A., Lanciotti, R.S., and Gubler, D.J. 2002. West Nile virus. Lancet Infect. Dis. 2:519-529.

47. Sejvar, J.J., et al. 2003. Neurologic manifestations and outcome of West Nile virus infection. JAMA. 290:511-515.

48. Petersen, L.R., Marfin, A.A., and Gubler, D.J. 2003. West Nile virus. JAMA. 290:524-528.

49. Roehrig, J.T., et al. 2003. Persistence of virus-reactive serum immunoglobulin $\mathrm{m}$ antibody in confirmed West Nile virus encephalitis cases. Emerg. Infect. Dis. 9:376-379.

50. Wong, S.J., et al. 2003. Immunoassay targeting nonstructural protein 5 to differentiate West Nile virus infection from dengue and St. Louis encephalitis virus infections and from flavivirus vaccination. J. Clin. Microbiol. 41:4217-4223.

51. Wong, S.J., et al. 2004. Detection of human anti-flavivirus antibodies with a West Nile virus recombinant antigen microsphere immunoassay. J. Clin. Microbiol. 42:65-72.

52. Mostashari, F., et al. 2001. Epidemic West Nile encephalitis, New York, 1999: results of a household-based seroepidemiological survey. Lancet. 358:261-264.

53. Nash, D., et al. 2001. The outbreak of West Nile virus infection in the New York City area in 1999. N. Engl. J. Med. 344:1807-1814.

54. Tsai, T.F., Popovici, F., Cernescu, C., Campbell, G.L., and Nedelcu, N.I. 1998. West Nile encephalitis epidemic in southeastern Romania. Lancet. 352:767-771.

55. Diamond, M.S., Shrestha, B., Marri, A., Mahan, D., and Engle, M. 2003. B cells and antibody play criti$\mathrm{cal}$ roles in the immediate defense of disseminated infection by West Nile encephalitis virus. J. Virol. 77:2578-2586.

56. Wang, T., et al. 2003. IFN-gamma-producing gamma delta $\mathrm{T}$ cells help control murine West Nile virus infection. J. Immunol. 171:2524-2531.

57. Wang, Y., Lobigs, M., Lee, E., and Mullbacher, A. 2003. CD8+ T cells mediate recovery and immunopathology in West Nile virus encephalitis. J. Virol. 77:13323-13334.

58. Anderson, J.F., and Rahal, J.J. 2002. Efficacy of interferon alpha-2b and ribavirin against West Nile virus in vitro. Emerg. Infect. Dis. 8:107-108.

59. Jordan, I., Briese, T., Fischer, N., Lau, J.Y., and Lipkin, W.I. 2000. Ribavirin inhibits West Nile virus replication and cytopathic effect in neural cells. J. Infect. Dis. 182:1214-1217.

60. Weiss, D., et al. 2001. Clinical findings of West Nile virus infection in hospitalized patients, New York and New Jersey, 2000. Emerg. Infect. Dis. 7:654-658.

61. Diamond, M.S., Shrestha, B., Mehlhop, E., Sitati, E., and Engle, M. 2003. Innate and adaptive immune responses determine protection against disseminated infection by West Nile encephalitis virus. Viral Immunol. 16:259-278.

62. Ben-Nathan, D., et al. 2003. Prophylactic and therapeutic efficacy of human intravenous immunoglobulin in treating West Nile virus infection in mice. J. Infect. Dis. 188:5-12.

63. Engle, M.J., and Diamond, M.S. 2003. Antibody prophylaxis and therapy against West Nile virus infection in wild-type and immunodeficient mice. J. Virol. 77:12941-12949.

64. Morens, D.M. 1994. Antibody-dependent enhancement of infection and the pathogenesis of viral disease. Clin. Infect. Dis. 19:500-512.

65. Shimoni, Z., Niven, M.J., Pitlick, S., and Bulvik, S. 2001. Treatment of West Nile virus encephalitis with intravenous immunoglobulin. Emerg. Infect. Dis. 7:759.

66. Hamdan, A., et al. 2002. Possible benefit of intravenous immunoglobulin therapy in a lung transplant recipient with West Nile virus encephalitis. Transpl. Infect. Dis. 4:160-162.

67. Haley, M., Retter, A.S., Fowler, D., Gea-Banacloche, J., and O'Grady, N.P. 2003. The role for intravenous immunoglobulin in the treatment of West Nile virus encephalitis. Clin. Infect. Dis. 37:e88-e90.

68. Agrawal, A.G., and Petersen, L.R. 2003. Human immunoglobulin as a treatment for West Nile virus infection. J. Infect. Dis. 188:1-4.

69. Roehrig, J.T., Staudinger, L.A., Hunt, A.R., Mathews, J.H., and Blair, C.D. 2001. Antibody prophylaxis and therapy for flavivirus encephalitis infections. Ann. N. Y. Acad. Sci. 951:286-297.

70. Tesh, R.B., Travassos da Rosa, A.P., Guzman, H., Araujo, T.P., and Xiao, S.Y. 2002. Immunization with heterologous flaviviruses protective against fatal West Nile encephalitis. Emerg. Infect. Dis. 8:245-251.

71. Ng, T., et al. 2003. Equine vaccine for West Nile virus. Dev. Biol. 114:221-227.

72. Pletnev, A.G., et al. 2003. Molecularly engineered live-attenuated chimeric West Nile/dengue virus vaccines protect rhesus monkeys from West Nile virus. Virology. 314:190-195.

73. Lustig, S., et al. 2000. A live attenuated West Nile virus strain as a potential veterinary vaccine. Viral Immunol. 13:401-410.

74. Chambers, T.J., Halevy, M., Nestorowicz, A., Rice,
C.M., and Lustig, S. 1998. West Nile virus envelope proteins: nucleotide sequence analysis of strains differing in mouse neuroinvasiveness. J. Gen. Virol. 79:2375-2380.

75. Konishi, E., Yamaoka, M., Khin-Sane, W., Kurane, I., and Mason, P.W. 1998. Induction of protective immunity against Japanese encephalitis in mice by immunization with a plasmid encoding Japanese encephalitis virus premembrane and envelope genes. J. Virol. 72:4925-4930.

76. Arroyo, J., Miller, C.A., Catalan, J., and Monath, T.P. 2001. Yellow fever vector live-virus vaccines: West Nile virus vaccine development. Trends Mol. Med. 7:350-354.

77. Monath, T.P., Arroyo, J., Miller, C., and Guirakhoo, F. 2001. West Nile virus vaccine. Curr. Drug Targets Infect. Disord. 1:37-50.

78. Tesh, R.B., et al. 2002. Efficacy of killed virus vaccine, live attenuated chimeric virus vaccine, and passive immunization for prevention of West Nile virus encephalitis in hamster model. Emerg. Infect. Dis. 8:1392-1397.

79. Davis, B.S., et al. 2001. West Nile virus recombinant DNA vaccine protects mouse and horse from virus challenge and expresses in vitro a noninfectious recombinant antigen that can be used in enzyme-linked immunosorbent assays. J. Virol. 75:4040-4047.

80. Yang, J.S., et al. 2001. Induction of potent Th1-type immune responses from a novel DNA vaccine for West Nile virus New York isolate (WNV-NY1999). J. Infect. Dis. 184:809-816. Epub 2001 Aug 2029.

81. Wang, T., et al. 2001. Immunization of mice against West Nile virus with recombinant envelope protein. J. Immunol. 167:5273-5277.

82. Takasaki, T., et al. 2003. Partial protective effect of inactivated Japanese encephalitis vaccine on lethal West Nile virus infection in mice. Vaccine. 21:4514-4518.

83. Kanesa-Thasan, N., Putnak, J.R., Mangiafico, J.A., Saluzzo, J.F., and Ludwig, G.V. 2002. Short report: absence of protective neutralizing antibodies to West Nile virus in subjects following vaccination with Japanese encephalitis or dengue vaccines. Am. J. Trop. Med. Hyg. 66:115-116.

84. Hall, R.A., et al. 2003. DNA vaccine coding for the full-length infectious Kunjin virus RNA protects mice against the New York strain of West Nile virus. Proc. Natl. Acad. Sci. U. S. A. 100:10460-10464.

85. Monath, T.P. 1980. Epidemiology. In St. Lowis Encephalitis. T.P. Monath, editor. American Public Health Association. Washington, DC, USA. 239-312. 